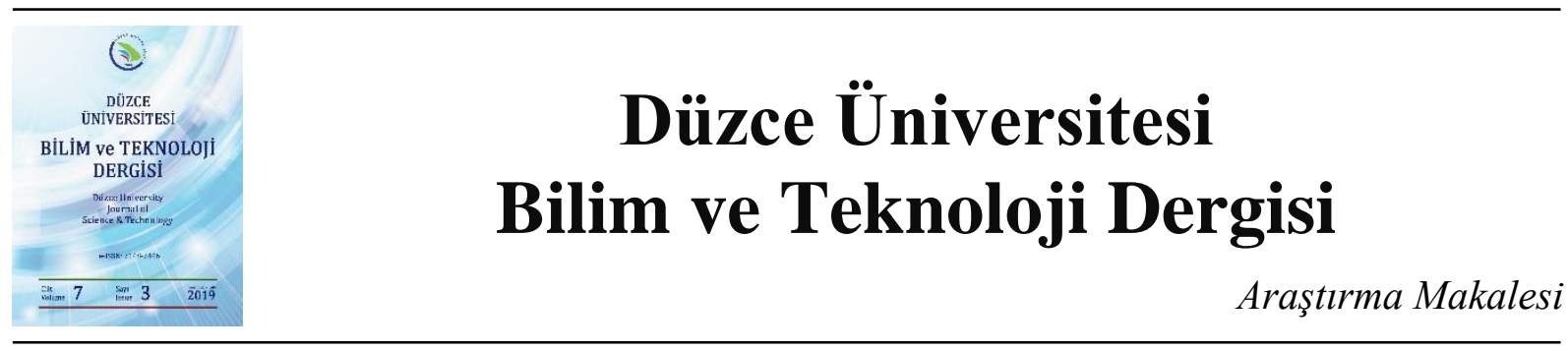

\section{Ultrasonik Sprey Piroliz ile Üretilen Flor Katkılı Kalay Oksit İnce Filmlerin Yapısal, Morfolojik, Optiksel ve Elektriksel Analizleri}

(iD) Murat KALELì ${ }^{\mathrm{a}}$,* (iD) Durmuş Ali ALDEMİR ${ }^{\mathrm{a}}$, (D) Ahmet Buğrahan BAYRAM ${ }^{\mathrm{b}}$, (iD) Celal Alp YAVRU $^{\mathrm{b}}$

${ }^{a}$ Fizik Bölümü, Fen Edebiyat Fakültesi, Süleyman Demirel Üniversitesi, Isparta, TÜRKIYE

${ }^{b}$ Fizik Anabilim Dal, Fen Bilimleri Enstitüsü, Süleyman Demirel Üniversitesi, Isparta, TÜRKIYE

* Sorumlu yazarin e-posta adresi: muratkaleli@sdu.edu.tr

DOI : $10.29130 /$ dubited.549547

\begin{abstract}
ÖZET
Bu çalışmada yüksek şeffaflığa sahip Flor katkılı Kalay Oksit ince filmleri ultrasonik sprey piroliz tekniği ile başarılı bir şekilde üretilmiştir. İnce filmlerin yapısal ve morfolojik karakterizasyonu için X-ışını kırınımı, taramalı elektron mikroskobu ve atomik kuvvet mikroskobu analizleri yapılmıştır. X-ışını kııınımı desenleri göstermiştir ki filmler polikristal haldedir ve (200) tercihli yönelimi boyunca büyümüşlerdir. 3,16 eV'luk bir band aralığı UV-Vis ölçümlerinden elde edilmiştir. İnce filmlerin öz direnci $1,35 \times 10^{-3} \Omega$-cm olarak bulunmuştur.
\end{abstract}

Anahtar Kelimeler: Flor katkllı Kalay Oksit, Ultrasonik sprey piroliz, Fiziksel özellikler

\section{Structural, Morphological, Optical and Electrical Analysis of Fluorine Doped Tin Oxide Thin Films Fabricated by Ultrasonic Spray Pyrolysis}

\begin{abstract}
In this study, Fluorine doped Tin Oxide (FTO) thin films with high transparency were fabricated by ultrasonic spray pyrolysis technique, successfully. The analysis of X-ray diffraction, scanning electron microscopy and atomic force microscopy were used for the structural and morphological characterization of the thin films. X-ray diffraction patterns showed that the films were polycrystalline and grow along to preferred orientation of (200). The band gap value of $3.16 \mathrm{eV}$ was obtained from UV-Vis measurements. The resistivity of the thin films was found to be as $1.35 \times 10^{-3} \Omega-\mathrm{cm}$.
\end{abstract}

Keywords: Fluorine doped Tin Oxide, Ultrasonic Spray Pyrolysis, Physical properties

Geliş: 04/04/2019, Düzeltme: 16/07/2019, Kabul: 17/07/2019 


\section{GiRISS}

B ilindiği gibi geniş band aralığına sahip oksit yariiletkenler görünür ve mor ötesi bölgede yüksek geçirgenliğe sahiptir ve oda sıcaklığında klasik yalıtkanlar gibi davranırlar. Stokiyometriden saptırmalarla veya uygun malzemelerle katkılama yapılmasıyla bu tip yariletkenleri iyi bir iletken haline getirmek mümkündür [1]. Kalay katk1lı Indiyum Oksit $\left(\operatorname{In}_{2} \mathrm{O}_{3}: \mathrm{Sn}\right)$ ve Flor katk1lı Kalay Oksit $\left(\mathrm{SnO}_{2}: \mathrm{F}\right)$ filmler bu yöntemlerle elde edilmiş şeffaf iletken malzemelerdir ve literatürde sırasıyla ITO ve FTO olarak isimlendirilirler. ITO ve FTO filmler başta güneş hücresi uygulamaları olmak üzere elektromanyetik zırhlama, gaz sensörleri, dokunmatik panel, polimer tabanlı LED’ler gibi uygulamalarda yaygın bir biçimde kullanılmaktadır [2-6]. ITO filmlerden daha düşük bir iletkenliğe sahip olsalar da, FTO filmler yüksek 1sı dayanımı ve kimyasal kararlılıklarından dolayı ITO filmlere nazaran daha çok tercih edilirler. Bu yönleri ile FTO filmler özellikle güneş hücresi uygulamalarında ön plandadırlar $[6,7]$.

FTO filmler; kimyasal buhar biriktirme [8], manyetik saçtırma [9], sol-jel [10], sprey piroliz [11], alev-destekli sprey [12] ve ultrasonik sprey piroliz (USP) [13] gibi çok farklı yöntemlerle üretilebilmektedir. Bu yöntemler içerisinde USP yönteminde, piezoelektrik aygitlar aracıllı̆ $\breve{1}_{1}$ ile $\mathrm{kHz}$ mertebesinde frekanslarda titreşmekte olan nozul içerisinden geçen solüsyon, bu yüksek frekans ile ters orantılı olarak, alttaş üzerine düşen damlacık boyutunun daha da küçültülmesine olanak sağlamakta ve bu sayede çok daha homojen kaplamalar yapılabilmektedir. Bununla beraber USP sistemleri nozul frekansı, solüsyon akış hızı, nozul- alttaş arası mesafe ve üretim esnasında ortamın oksijen/nem seviyesinin ayarlanabilmesi gibi farklı ve esnek üretim parametrelerine sahip olmas1 sebebiyle son yıllarda araştırmacıların ilgisini çekmektedir. Ayrıca USP; deneysel düzeneğinin basit oluşu, malzemenin istenilen oranlarda katkılanabilmesi, geniş alanlarda homojen, ucuz ve kolay üretim yapılabilmesi gibi özellikleri ile öne çıkmaktadır [1, 14, 15].

$\mathrm{Bu}$ çalışmada; elektro optik uygulamalar için uygun, yüzey pürüzlülüğü düşük, şeffaf ve iletken SnO2:F ince filmler ultrasonik sprey yöntemi ile üretilmiş ve üretilen filmlerin optiksel, elektriksel, yapısal ve morfolojik karakterizasyonları gerçekleştirilmiştir. FTO ince filmlerin USP yöntemiyle geniş alan uygulamaları için optimum üretim şartları belirlenmeye çalışılmıştır.

\section{DENEYSEL PROSEDÜR}

FTO (Flor katkılı Kalay Oksit) kaplanacak cam alttaşlar $\left(76 \times 26 \times 1 \mathrm{~mm}^{3}\right)$ farklı ebatlarda kesildikten sonra sirasiyla aseton, etanol, izopropil alkol ve tolüen kullanilarak organik kirliliklerden arındırılmıştır. Her bir çözücünün ardından alttaşlar ultra saf su ile durulanmıştır. Kalay öncüsü (prekürsör) olarak $\mathrm{SnCl}_{4} \cdot 5 \mathrm{H}_{2} \mathrm{O}$ (stannic chloride) ve Flor kaynağı olarak amonyum florür $\left(\mathrm{NH}_{4} \mathrm{~F}\right)$ kullanılmıştır. Sprey solüsyonunu hazırlamak için 3,606 g Kalay öncüsü $50 \mathrm{ml}$ metanol içerisinde

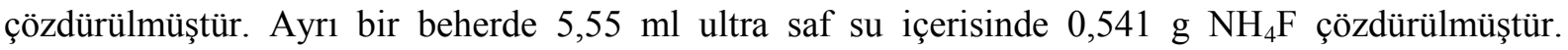
Böylece kütlece $\left[\mathrm{NH}_{4} \mathrm{~F}\right] /\left[\mathrm{SnCl}_{4} \cdot 5 \mathrm{H}_{2} \mathrm{O}\right]$ oranı \%15'e ayarlanmıştır. İki ayrı çözelti tek bir beherde 
birleştirilerek $15 \mathrm{dk}$ boyunca manyetik karıştırıcıda karıştırılmıştır ve daha sonra çözelti filtreden geçirilmiştir. Alttaş sıcaklığı $380{ }^{\circ} \mathrm{C}$ 'ye sabitlikten sonra cam yüzeyleri ultrasonik sprey piroliz (USP) yöntemi ile kaplanmıştır. Kaplama işlemi bittikten sonra örnekler oda sıcaklığında soğumaya bırakılmıştır. Kaplama parametreleri Tablo 1'de özetlenmiştir. Kaplama alanı yaklaşık olarak $6 \times 6$ $\mathrm{cm}^{2}$ 'dir. Nozul kafası bu alanı 41 saniye içerisinde önce enine ve sonra boyuna olarak taramaktadır ve bu sayede alan içerisindeki cam yüzeylerine filmlerin homojen şekilde biriktirilmesi sağlanmaktadır. $\mathrm{Bu}$ işlem kaplama sayısı olarak ifade edilmektedir.

Filmlerin morfolojisi; FEI Quanta FEG 250 marka taramalı elektron mikroskobu (SEM) ve Nanomagnetic ez-AFM marka atomik kuvvet mikroskobu (AFM) kullanılarak incelenmiştir. X-1şını kırınımı (XRD) ölçümleri Bruker D8 Advance Twin-twin cihazı ile alınmıştır ve yine EVA yazılımı ve ICDD veri tabanı vasıtasıyla analizleri gerçekleştirilmiştir. UV-Visible ölçümleri ise PGInstruments firmasının T80+ UV/VIS spektrofotometresi ile gerçekleştirilmiştir.

Tablo 1. FTO ince filmlerin üretiminde kullanılan kaplama parametreleri

\begin{tabular}{lc}
\hline Alttaş sıcaklığı & $380{ }^{\circ} \mathrm{C}$ \\
\hline Alttaş-nozul mesafesi & $12 \mathrm{~cm}$ \\
\hline Nozul frekansı & $120 \mathrm{kHz}$ \\
\hline Akış hızı & $1 \mathrm{ml} / \mathrm{dk}$ \\
\hline Oksijen oranı & $\% 14-15$ \\
\hline Nozul soğutma & $15 \mathrm{psi}$ \\
\hline Motor soğutma & $2 \mathrm{psi}$ \\
\hline Güç & $8 \mathrm{~W}$ \\
\hline
\end{tabular}

\section{BULGULAR Ve TARTIȘMA}

Şekil 1'de ultrasonik sprey piroliz (USP) yöntemi ile üretilen Flor katkılı Kalay Oksit (FTO) filmlerinin resimleri verilmektedir. Filmlerin yapisal, morfolojik, optiksel ve elektriksel karakterizasyonları gerçekleştirilmiştir.

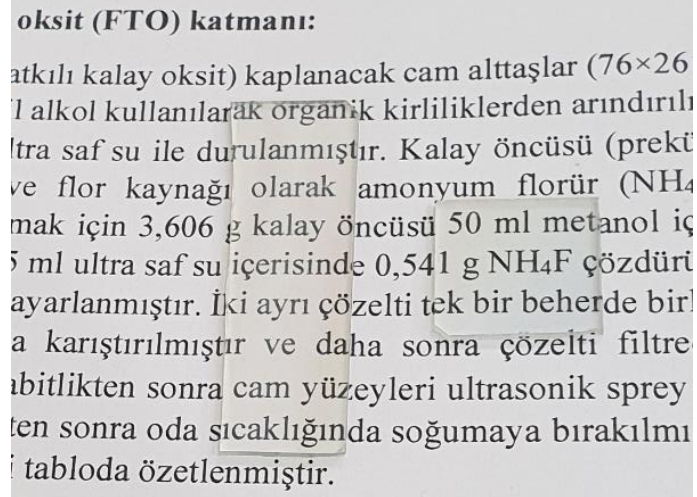

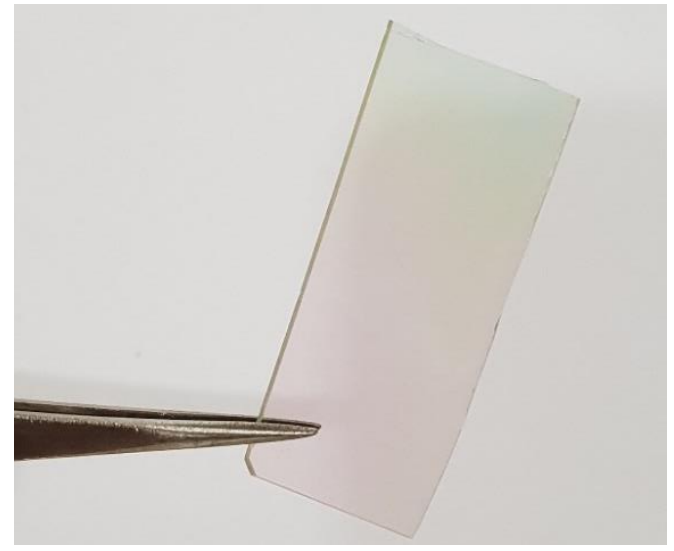

Şekil 1. Cam üzerine kaplanmış Flor katkılı Kalay Oksit filmler 
Şekil 2'de cam üzerine ultrasonik sprey yöntemi ile biriktirilmiş FTO ince filmlerine ait XRD deseni verilmiştir. Desendeki pikler karakteristik $\mathrm{SnO}_{2}$ piklerine ve $\mathrm{Sn}_{4} \mathrm{OF}_{6}$ pikine karş1lık gelmektedirler. Referans olarak PDF 00-046-1088, PDF 01-075-9498, PDF 00-003-1116 ve PDF 01-082-2194 kartlar1 kullanılmıştır. Şekil 2'den görülebileceği gibi sentezlenen ince filmlerde farklı kristal yapıları mevcuttur. Polikristal haldeki tetragonal yapılı filmlerin tercihli yönelimi (200)'dır. Bu ana pikin EVA yazılımı vasıtasıyla yapılan analizi sonucu kristal boyutu $9,28 \mathrm{~nm}$ bulunmuştur.

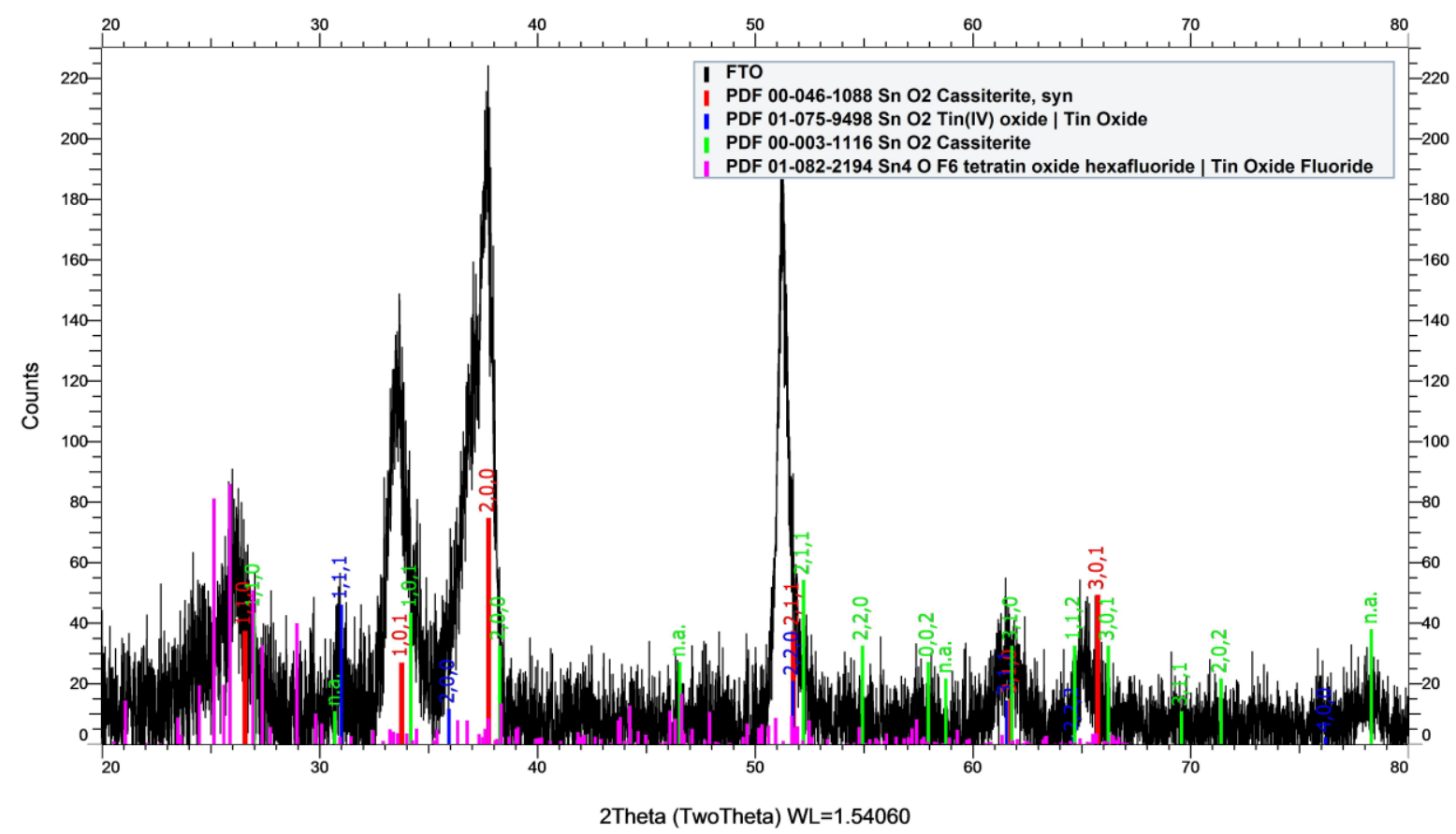

Şekil 2. Cam üzerine biriktirilmiş FTO ince filmlerinin XRD deseni

Şekil 3'te cam üzerine biriktirilmiş Flor katk1l $\mathrm{SnO}_{2}$ ince filmlerinin yüzeylerine ait $\times 50000$ ve $\times 100000$ büyütmelerde alınmış SEM görüntüleri verilmiştir. Yüzey resimlerinden görülebileceği üzere FTO filmleri homojen bir yüzeye sahiptir. Adacık boyutları ise $90 \mathrm{~nm}$ ile $110 \mathrm{~nm}$ arasında değişim göstermektedir. $\mathrm{Bu}$ değerler XRD analizleri sonucu bulunan kristal boyutundan oldukça büyüktür. SEM yüzey görüntülerinde elde edilen adacık boyutlarının XRD sonuçlarında elde edilen kristal boyutundan daha büyük olmasının sebebi yüzeyde farklı FTO fazları nedeniyle oluşan polikristal adacıkların varlığına atfedilebilir.
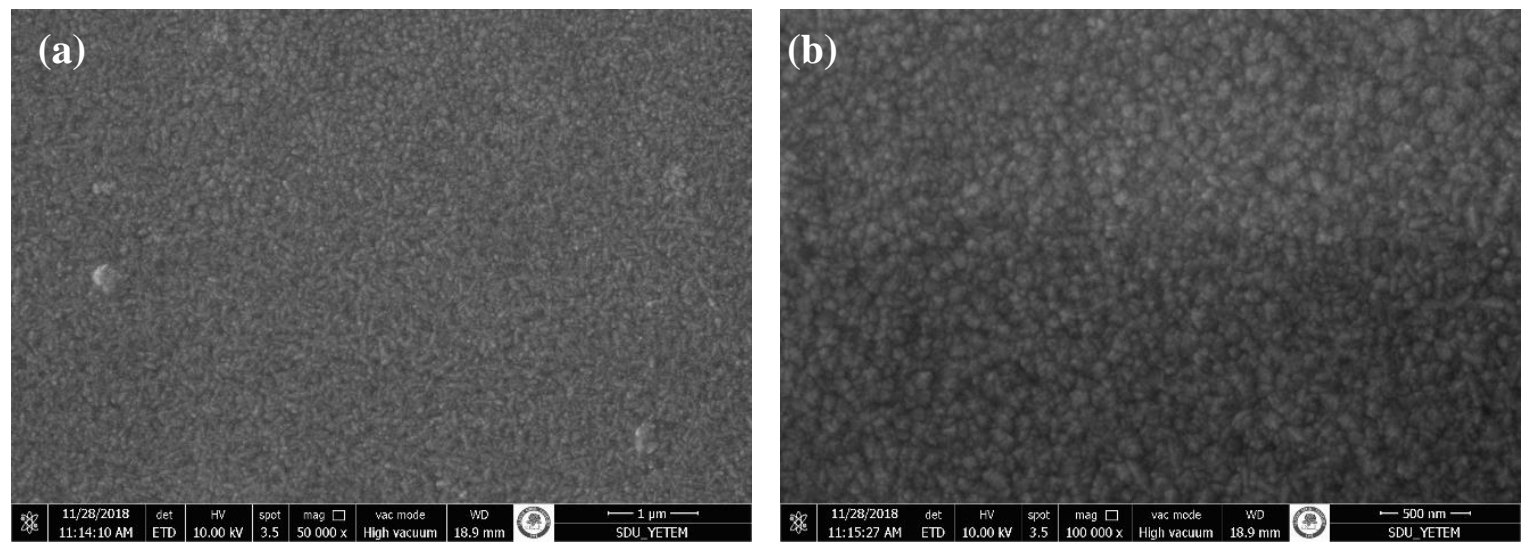

Şekil 3. FTO ince filmlerine ait sırasıyla $\times 50000$ ve $\times 100000$ büyütmelerdeki SEM görüntüleri a) ölçek 1 um b) ölçek $500 \mathrm{~nm}$ 
Kalınlık optimizasyonunun gerçekleştirilebilmesi açısından farklı kaplama sayısı sayılarında biriktirilmiş FTO filmlerinin kesit görüntüleri SEM vasıtasıyla alınmıştır. Şekil 4.a'da 21 kaplama sayısı (pass) ve Şekil 4.b'de 41 kaplama sayısı sonucu üretilmiş olan filmlerin kesit görüntüleri verilmiştir. Filmlerin kesit görüntüleri incelendiğinde film kalınlığının, film boyunca hemen hemen aynı olduğu görülebilmektedir. Ortalama kalınlık 21 kaplama sayısı için 156 nm iken 41 kaplama sayısı için $340 \mathrm{~nm}$ olarak belirlenmiştir. Bu veriler göz önüne alındığında her bir kaplama sayısı için ortalama olarak $8 \mathrm{~nm}$ kalınlığında bir FTO tabakasının biriktirildiği söylenebilir.
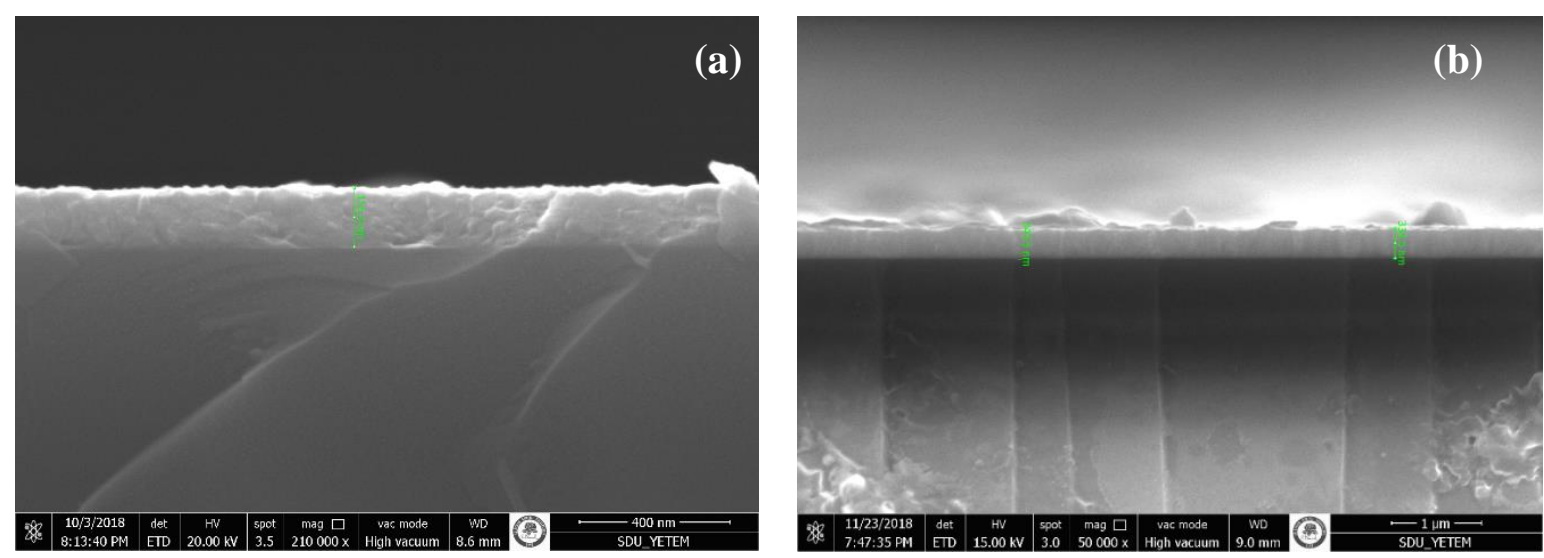

Şekil 4. Cam üzerine biriktirilmiş FTO filmlerinin kesit görüntüleri a) 21 kaplama sayısı (×210000 büyütme) b) 41 kaplama sayısı (×50000 büyütme)

Şekil 5'te $340 \mathrm{~nm}$ kalınlığa sahip FTO ince filminin optik geçirgenliğinin (\%T) ve soğurma katsayısının $(\alpha)$ dalga boyuna karşı grafiği görülmektedir. Grafikten görülebileceği üzere üretilen ince film görünür bölgede en düşük \%86,5 (390 nm) ve en yüksek \%95,7 (586 nm) oranında bir optik geçirgenliğe sahiptir. Bu değerler, saydam iletken oksitlerin (TCO) optoelektronik uygulamalarda kullanılabilmesi için gerekli olan \%80 [9] değerinin çok üstündedir. Soğurma katsayıs1; Beer-Lambert yasası kullanılarak optik geçirgenlik verilerinden aşağıda verilen eşitlik yardımıyla hesaplanmaktadır [16]:

$\alpha=\frac{1}{d} \ln \left(\frac{100}{\% T}\right)$

Burada $d$ filmin kalınlığıdır. 


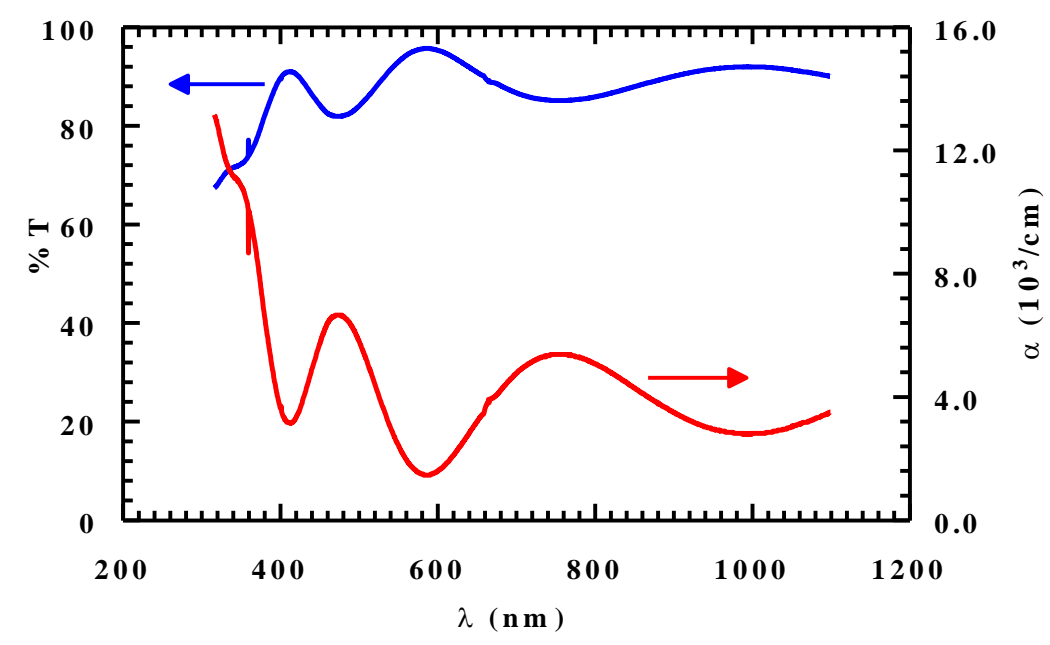

Şekil 5. FTO ince filminin optik geçirgenliğinin ve soğurma katsayısının dalgaboyuna göre grafiği

FTO direk band aralığına sahip bir yariiletkendir. Literatürde; FTO ince filmi için 3,17 ile 4,25 eV arasında band aralığı değerleri rapor edilmiştir [3, 9, 17]. Direk band aralığına sahip bir yariiletkenin soğurma katsayısı yardımıyla band aralığını belirleyebilmek için Tauc tarafından verilen aşağıdaki denklem yaygin olarak kullanılır [18]:

$(\alpha h v)^{2}=\beta\left(h v-E_{g}\right)$

Burada $h$ Planck sabiti, $v$ frekans, $E_{g}$ yariiletkeninin yasak band aralığı ve $\beta$ bir sabittir. Şekil 6'da kalınlığı $340 \mathrm{~nm}$ olan FTO ince filmine ait Tauc grafiği verilmiştir. Bu grafiğin lineer kısmına yapılan fitten band aralığı 3,16 eV hesaplanmıştır. Bu değer literatürde FTO için rapor edilen değerlerle uyum içindedir.

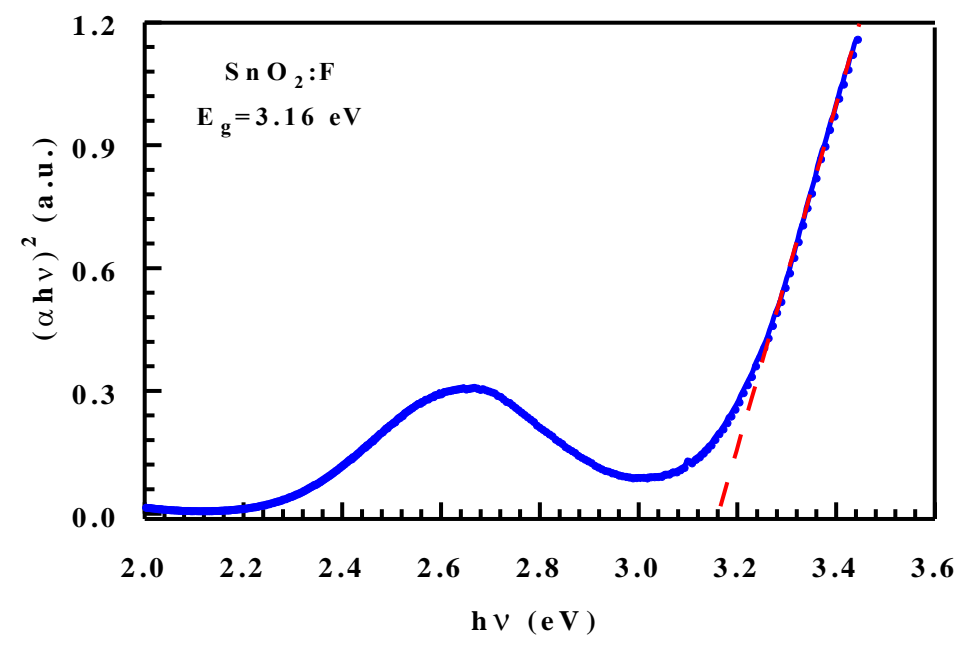

Şekil 6. FTO ince filmine ait Tauc eğrisi

340 nm kalınlığa sahip FTO ince filmlerinin Van der Pauw metodu ile direnci (sheet resistance) 39,8 $\Omega / \square$ olarak belirlenmiştir. Buradan FTO ince filmlerinin özdirenci $1,35 \times 10^{-3} \Omega$-cm olarak hesaplanmıştır. Literatürde farklı yöntemlerle üretilmiş FTO filmler için rapor edilmiş özdirenç değerleri Tablo 2'de verilmiştir. Tablodan görülebileceği üzere üretilen FTO filmlerinin özdirenci kabul edilebilir seviyelerdedir. 
Tablo 2. Literatürde farkl yöntemlerle üretilmiş FTO filmlerine ait özdirenç değerleri

\begin{tabular}{lcc}
\hline Yöntem & $\boldsymbol{\rho}\left(\mathbf{1 0}^{-3} \mathbf{\Omega} \cdot \mathbf{c m}\right)$ & Referans \\
\hline Ultrasonik sprey piroliz & 0,62 & {$[13]$} \\
\hline Sprey piroliz & $0,22-0,47$ & {$[3]$} \\
\hline Magnetik saçtırma & 6,71 & {$[9]$} \\
\hline
\end{tabular}

Son olarak atomik kuvvet mikroskobu (AFM) ile FTO ince filmlerinin yüzeyi için pürüzlülük araştırması yapılmıştır. FTO ince filminin AFM görüntüsü Şekil 7' de sırasıyla iki boyutlu ve üç boyutlu olarak gösterilmektedir. FTO ince filmlerin ortalama yüzey pürüzlülügü $\left(\mathrm{R}_{\mathrm{a}}=1,93 \mathrm{~nm}\right)$ olarak tespit edilmiştir.
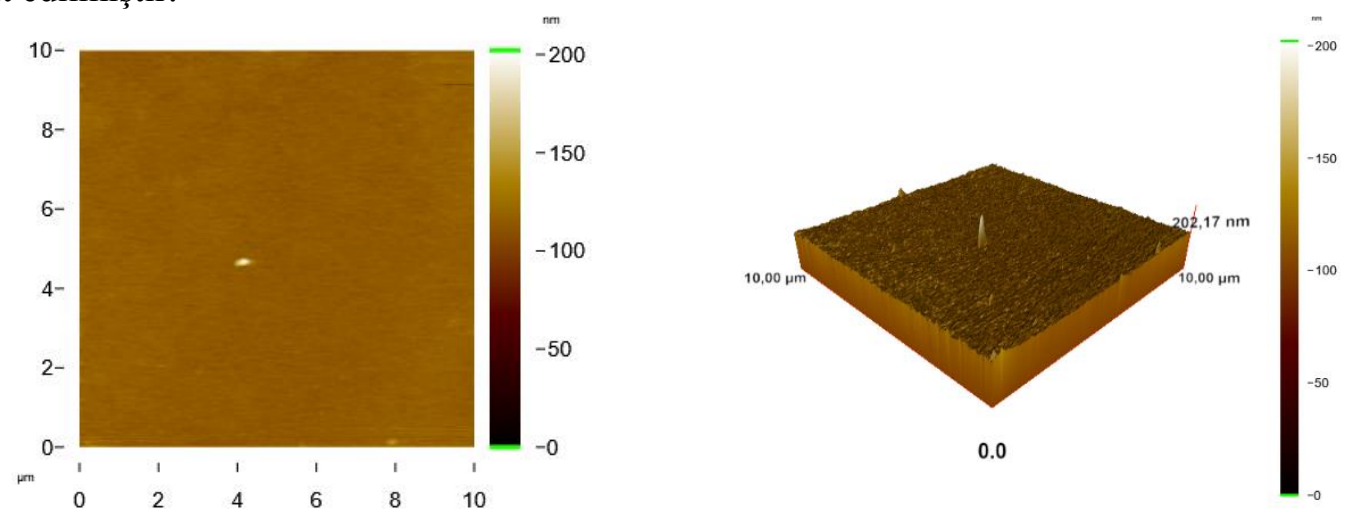

Şekil 7. FTO ince filmlerinin sirasiyla 2 ve 3 boyutlu AFM görüntüleri

\section{SONUC}

Utrasonik sprey piroliz yöntemi ile sentezlenen FTO filmlerin yapısal, morfolojik, optiksel ve elektriksel analizleri yapılmıştır. XRD ölçümlerinden, sentezlenen filmlerin polikristal bir yapı sergilediği ve tetragonal bir kristal örgüsüne sahip olduğu görülmüştür. (200) ana pikinin analizi sonucu kristal boyutu 9,28 nm olarak belirlenmiştir. Üretim sırasındaki kaplama sayısı sayısına bağlı olarak FTO ince filmlerinin kalınlık optimizasyonu gerçekleştirilmiştir. SEM görüntülerden filmlerin homojen bir yüzeye sahip olduğu görülmüştür. Filmler görünür bölgede güneş hücrelerinde kullanabilmesine imkân tanır vaziyette çok iyi bir optik geçirgenlik sergilemiştir. Band aralığı 3,16 eV olarak hesaplanmıştır. AFM ölçümleri vasıtasıyla FTO ince filmlerinin ortalama yüzey pürüzlüğü 1,93 nm olarak belirlenmiştir.

TEȘEKKÜR: $\mathrm{Bu}$ çalışma 3501-Kariyer Geliştirme Programı kapsamında TUBİTAK tarafından desteklenmiştir (Proje no: 117F417).

\section{KAYNAKLAR}

[1] O. Malik, F. J. De la Hidalga-Wade, and R. R. Amador, 'Fluorine-doped Tin Oxide Films with 
A High Figure of Merit Fabricated by Spray Pyrolysis,' Journal of Materials Research, vol. 30, no. 13, pp. 2040-2045, 2015.

[2] T. Jäger, B. Bissig, M. Döbeli, A. N. Tiwari, and Y. E. Romanyuk, 'Thin films of SnO2:F by Reactive Magnetron Sputtering with Rapid Thermal Post-Annealing,' Thin Solid Films, vol. 553, pp. 21-25, 2014.

[3] A. E. Rakhshani, Y. Makdisi, and H. A. Ramazaniyan, 'Electronic and Optical Properties of Fluorine-Doped Tin Oxide Films,' Journal of Applied Physics, vol. 83, no. 2, pp. 1049-1057, 1998.

[4] K. Nomura, Y. Ujihira, S. S. Sharma, A. Fueda, and T. Murakami, 'Gas Sensitivity of Metal Oxide Mixed Tin Oxide Films Prepared by Spray Pyrolysis,' Journal of Materials Science, vol. 24, no. 3, pp. 2653-2658, 1989.

[5] A. Abdelkrim, S. Rahmane, O. Abdelouahab, N. Abdelmalek, and G. Brahim, 'Effect of Solution Concentration on The Structural, Optical and Electrical Properties of SnO2 Thin Films Prepared by Spray Pyrolysis,' Optik (Stuttg), vol. 127, no. 5, pp. 2653-2658, 2016.

[6] A. Andersson et al., 'Fluorine Tin Oxide as an Alternative to Indium Tin Oxide in Polymer LEDs,' Advanced Materials, vol. 10, no. 11, pp. 859-863, 1998.

[7] T. Fukano and T. Motohiro, 'Low-temperature Growth of Highly Crystallized Transparent Conductive Fluorine-Doped Tin Oxide Films by İntermittent Spray Pyrolysis Deposition,' Solar Energy Materials and Solar Cells, 2004.

[8] J. W. Bae, S. W. Lee, and G. Y. Yeom, 'Doped-Fluorine on Electrical and Optical Properties of Tin Oxide Films Grown by Ozone-Assisted Thermal CVD,' Journal of The Electrochemical Society, vol. 154, no. 1, p. D34, 2006.

[9] Z. Banyamin, P. Kelly, G. West, and J. Boardman, 'Electrical and Optical Properties of Fluorine Doped Tin Oxide Thin Films Prepared by Magnetron Sputtering,' Coatings, vol. 4, no. 4, pp. 732-746, 2014.

[10] A. N. Banerjee, S. Kundoo, P. Saha, and K. K. Chattopadhyay, 'Synthesis and Characterization of Nano-Crystalline Fluorine-Doped Tin Oxide Thin Films by Sol-Gel Method', Journal of Sol-Gel Science and Technology, vol. 28, no. 1, pp. 105-110, 2003.

[11] B. Thangaraju, 'Structural and Electrical Studies On Highly Conducting Spray Deposited Fluorine And Antimony Doped SnO2 Thin Films from SnCl2 Precursor,' Thin Solid Films, vol. 402, no. 1-2, pp. 71-78, 2002.

[12] A. Purwanto, H. Widiyandari, and A. Jumari, 'Fabrication of High-Performance Fluorine Doped-Tin Oxide Film Using Flame-Assisted Spray Deposition,' Thin Solid Films, vol. 520, no. 6, pp. 2092-2095, 2012.

[13] C. C. Lin, M. C. Chiang, and Y. W. Chen, 'Temperature Dependence of Fluorine-doped Tin Oxide Films Produced by Ultrasonic Spray Pyrolysis,' Thin Solid Films, vol. 518, no. 4, pp. 1241$1244,2009$. 
[14] S. Kose et al., 'Electrical, Structural and Surface Properties of Fluorine Doped Tin Oxide Films,' Applied Surface Science, vol. 256, no. 22, pp. 6586-6591, 2010.

[15] L. H. Lalasari, T. Arini, L. Andriyah, F. Firdiyono, and A. H. Yuwono, 'Electrical, Optical and Structural Properties of FTO Thin Films Fabricated by Spray Ultrasonic Nebulizer Technique from SnCl4 Precursor,' AIP Conference Proceedings, p. 020001, 2018.

[16] T. Şimşek, K. Gökşen, 'Çeşitli Gaz Akış Hızı Koşullarında Üretilen Hidrojenlenmiş Amorf Karbon İnce Filmlerin Optik Bant Aralıklarının İncelenmesi,' Düzce Üniversitesi Bilim ve Teknoloji Dergisi, cilt. 5, pp. 84-95, 2017.

[17] E. Elangovan and K. Ramamurthi, 'Studies on Micro-Structural and Electrical Properties of Spray-Deposited Fluorine-Doped Tin Oxide Thin Films From Low-Cost Precursor,' Thin Solid Films, vol. 476, no. 2, pp. 231-236, 2005.

[18] B. D. Viezbicke, S. Patel, B. E. Davis, and P. Birnie, 'Evaluation of the Tauc Method for Optical Absorption Edge Determination: ZnO Thin Films as a Model System,' Physica Status Solidi (b), vol. 252, no. 8, pp. 1700-1710, 2015. 